\title{
Association between the hemodialysis adequacy and sexual dysfunction in chronic renal failure: a preliminary study
}

\author{
Jae Heon Kim', Seung Whan Doo', Won Jae Yang ${ }^{1}$, Soon Hyo Kwon², Eun Seop Song ${ }^{3}$, Hong Jun Lee ${ }^{4}$, \\ Ik Sung Lim ${ }^{5}$, Hyun Hwang ${ }^{6}$ and Yun Seob Song ${ }^{1 *}$
}

\begin{abstract}
Background: The core question of the study was whether adequately achieved HD affected the sexual dysfunction in women on hemodialysis (HD) with chronic renal failure (CRF).

Methods: Thirty-seven female patients on HD, including 18 women with adequate HD and 19 women with non-adequate HD, and 36 healthy controls were included in this study. Demographic and clinical variables, including the sexual hormones estradiol and testosterone, were recorded. Sexual function was assessed according to the Female Sexual Function Index (FSFI) and results were compared between groups. Adequate HD was defined as an average urea clearance of over $1.3(\mathrm{Kt} / \mathrm{N})$ over three consecutive months.

Results: All domains of the FSFI questionnaire, with the exception of satisfaction, were higher in the control group than in the HD group. In comparing the adequate and non-adequate HD groups, there was no difference in any of the six domains of the FSDI questionnaire. Among the clinical variables, the number of menopausal women was higher in the HD group than in the control group $(P=0.023)$. Estradiol and testosterone levels were higher in the control group than in the HD group ( $P=0.003,0.027$, respectively). The number of menopausal women and estradiol and testosterone levels showed no differences between the adequate and non-adequate HD groups. Correlation analysis between Kt/N and FSFI showed no significant relationship, but estrogen did show a significant relationship with FSFI (correlation coefficient $=0.399, P=0.001$ ).
\end{abstract}

Conclusions: HD adequacy alone does not have a significant impact on sexual dysfunction. Other treatments options should be considered to treat sexual dysfunction in women with CRF.

Keywords: Hemodialysis, Hemodialysis adequacy, Urea clearance, Female, Sexual dysfunction

\section{Background}

Female sexual dysfunction is common in women experiencing chronic renal failure (CRF) and is estimated to occur at a rate of $60-70 \%$ despite the use of dialysis [1,2].

Hemodialysis (HD) is the most commonly used option for dialysis, and often patients on HD have no choice but to continue HD until they undergo a kidney transplant (KT). Although there have been many reports regarding the improvement of sexual dysfunction after KT $[3,4]$, those outcomes are not consistent $[5,6]$, and

\footnotetext{
* Correspondence: yssong@schmc.ac.kr

'Department of Urology, Soonchunhyang University Hospital,

Soonchunhyang University College of Medicine, Seoul, Korea

Full list of author information is available at the end of the article
}

moreover, from the patients' perspective, the chance for a KT is not likely.

In HD patients, adequate HD is important because it enables the patient to live clinically asymptomatic and be reasonably active and to maintain correction of the altered metabolic and homeostatic components secondary to the loss of the kidney function [7]. Ultimately, adequacy of HD is related to reduced morbidity and mortality associated with CRF [7].

Urea clearance $(\mathrm{Kt} / \mathrm{V})$ is a fractional clearance and represents HD adequacy [8]. However, few studies have investigated whether HD adequacy can improve sexual function in women with CRF. The aim of this study was to assess the 
impact of HD adequacy on sexual dysfunction in women with CRF and on HD.

\section{Methods}

\section{Study sample}

From March 2008 to February 2011, a total of 37 consecutive married women with CRF who were on HD were eligible and willing to participate in the study. Healthy female volunteers $(n=36)$ from the health promotion center at Soonchunhyang University Hospital were included as controls.

Approval for this study was obtained from the Internal Review Board at Soonchunhyang University Hospital. The HD group was composed of patients receiving HD treatment three times a week for 4 hours at one dialysis procedure for at least 6 months at the HD center at Soonchunhyang University Hospital.

The eligibility criteria for inclusion were: between the ages of 18 and 60 years, female gender, married, sexually active, no psychiatric disease including depression in the previous 6 months, and the intellectual and mental capacity to understand and answer the questionnaire. Exclusion criteria were having undergone surgical menopause, having undergone pelvic surgery including hysterectomy, clinical depression or other major psychiatric disease and having used hormonal replacement therapy within the past 5 years. A total of 37 patients were included in this study (Figure 1).

\section{Clinical investigation}

All patients and controls provided informed consent and underwent detailed clinical examination including testing hemoglobin, testosterone and estradiol levels, and recording of urea clearance (Kt/V).

To limit the influence of fluctuations in plasma hormone levels, blood samples were always drawn at the same time of day (08:00 to 10:00 hours).

\section{Methodology}

This was a cross-sectional study. A single investigator conducted face-to-face interviews with all study participants using a structured questionnaire.

\section{FSFI questionnaire}

To obtain sexual function assessments, the patients were asked to answer the Female Sexual Function Index (FSFI) questionnaire after undergoing HD treatment. The FSFI is an instrument used for the assessment of sexual function and consists of 19 questions [9,10].

The FSFI has been validated based on the DSM IV diagnoses of desire disorder, arousal disorder, and orgasmic dysfunction, and is intended for patients that have been sexually active in the previous four weeks $[9,10]$. The FSFI been previously validated in the Korean language and in the Korean population [11]. The questions are grouped and scored for domains of desire (two questions), arousal (four questions), lubrication (four questions), orgasm

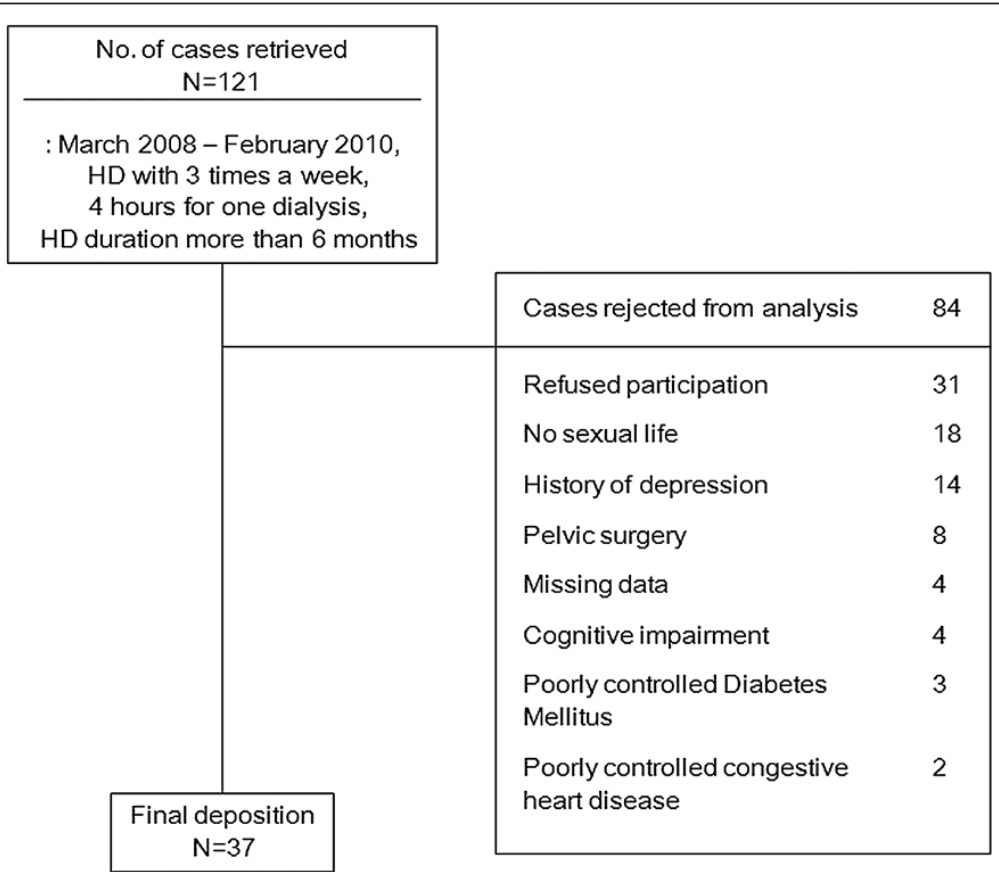

Figure 1 Patient deposition. 
(three questions), satisfaction (three questions), and pain (three questions). Each domain is scored on a scale of 0 to 6 , with higher scores indicating better function for each domain. A domain score of zero indicates that the women reported no sexual activity during the previous month and the full score ranges from 2 to 36. The individual domain scores are totaled and multiplied by a predetermined factor to weigh each domain equally.

\section{Assessment of urea clearance (Kt/V)}

Urea clearance $(\mathrm{Kt} / \mathrm{V})$ is a fractional clearance and is indicative of $\mathrm{HD}$ adequacy. [8] $\mathrm{Kt} / \mathrm{V}$ is calculated using the following natural logarithm formula: $\mathrm{Kt} / \mathrm{V}=-\mathrm{Ln}$ $(\mathrm{R}-0.008 \times \mathrm{t})+(4-3.5 \times \mathrm{R}) \times \mathrm{UF} / \mathrm{W}$, where $\mathrm{Ln}$ is the natural logarithm, $\mathrm{R}$ is the ratio between post-dialysis blood urea nitrogen (BUN) and pre-dialysis BUN, $t$ is the dialysis session length in hours, UF is the ultrafiltration volume in liters, and W is the patient's post-dialysis weight in kilograms.

\section{Definition of adequate HD}

Adequate HD was defined as over $1.3(\mathrm{Kt} / \mathrm{V})$ average urea clearance over three consecutive months. The Kidney Disease Outcomes Quality Initiative (KDOQI) guidelines (2006) recommend that the $\mathrm{Kt} / \mathrm{V}$ dose targets are 1.4 with a 1.2 minimum, and the Renal Association Clinical Practice guidelines recommend a single pool Kt/V of greater than 1.3 .

\section{Statistical analyses}

The Kolmogorov-Smirnov test was used to verify the normality of the distribution of continuous variables. Nonparametric comparison tests were used for variables evaluated as not normally distributed. Scores from the FSFI showed a nonparametric distribution; therefore, the mean value with standard deviation and the median value were used together as appropriate to describe statistics. Differences between groups were determined using the Kruskal-Wallis test and the Mann-Whitney test as appropriate. Spearmann's correlation test was used to investigate the association between $\mathrm{Kt} / \mathrm{V}$ and sexual functional scores. All statistics were two-tailed and a $P$ value $<0.05$ was considered significant. All calculations were performed using SPSS version 18.0 (SPSS, Chicargo, Ill., USA).

\section{Results}

Baseline analysis among the adequate HD, non-adequate $\mathrm{HD}$, and normal control groups

There were no differences in age and height between the control and patient groups. Body weight and body mass index were significantly lower in the CRF patient group. The underlying etiologies of renal failure were chronic glomerulonephritis $(n=6)$, diabetic nephropathy $(n=12)$, hypertensive nephropathy $(n=6)$, adult polycystic kidney $(n=1)$ and other etiologies $(n=11)$. The mean duration of HD was 8.1 years.

Demographic variables did not differ, with the exception of body mass index, which was higher in the control groups. The rate of menopause was significantly higher in the HD groups, and testosterone and estradiol showed higher levels in the control groups. The average single-pool $\mathrm{Kt} / \mathrm{V}$ in the adequate and non-adequate HD groups was $1.47 \pm 0.11$ and $1.14 \pm 0.05$, respectively (Table 1 ).

\section{Comparative analysis of FSFI scores among the adequate $H D$, non-adequate HD, and normal control groups}

When comparing the FSFI scores in the control and study groups, all domain scores except 'satisfaction', namely 'desire,' 'arousal,' 'lubrication,' 'orgasm,' 'pain' and 'total', were significantly lower in the HD groups than the scores of the control groups. The adequate and nonadequate groups did not differ in any of the domains or total FSFI (Table 2).

\section{Correlation analysis between $\mathrm{Kt} / \mathrm{V}$ and FSFI scores}

Spearman's correlation test was performed to evaluate the associations among the FSFI questionnaire and $\mathrm{Kt} / \mathrm{V}$. The correlation analysis showed no significant relationship between FSFI and Kt/V (Table 3).

\section{Correlation analysis between other factors and FSFI scores}

Age, duration of dialysis, body mass index and testosterone showed no significant correlation with FSFI scores. Estrogen showed a significant correlation with all FSFI domains: 'desire' $(P<0.001)$, 'arousal' $(P<0.001)$, 'lubrication' $(P<0.001)$, 'orgasm' $(P<0.001)$, 'satisfaction' $(P=0.047)$, 'pain' $(P=0.003)$, and 'total FSFI' $(P=0.001)$.

\section{Discussion}

Female patients with CRF often suffer from sexual dysfunction $[1,4]$. Sexual dysfunction in women with CRF is largely due to loss of sexual interest, difficulties with arousal and reaching orgasm, reduced libido and lubrication, and pain during intercourse $[1,12,13]$.

Considering that there are no other treatment options except $\mathrm{KT}$, maintaining $\mathrm{HD}$ is an important treatment strategy for patients with CRF. HD adequacy is directly related to a patient's well-being, including physical activity, and is directly related to mortality and morbidity [7]. Considering there is no standard protocol for treating sexual dysfunction in women with CRF on HD, one important motivation for this study arose from the need to investigate the impact of HD adequacy on female sexual dysfunction.

$\mathrm{Kt} / \mathrm{V}$, urea fractional clearance, is a standard method to assess HD adequacy. This kinetic model is a clear was of determining adequacy [8]. There have been few reports regarding the role of $\mathrm{Kt} / \mathrm{V}$ in female sexual dysfunction in 
Table 1 Patient characteristics

\begin{tabular}{|c|c|c|c|c|}
\hline & Controls $(n=36)$ & Adequate HD $(n=18)$ & Non-adequate HD $(n=19)$ & $P$ value \\
\hline Age (years) & $48.19 \pm 6.94$ & $47.89 \pm 6.82$ & $47.53 \pm 6.39$ & 0.671 \\
\hline Height (cm) & $155.65 \pm 5.46$ & $155.61 \pm 4.07$ & $155.741 \pm 4.50$ & 0.978 \\
\hline Weight [24] & $58.84 \pm 7.27$ & $56.11 \pm 9.46$ & $54.18 \pm 5.76$ & 0.052 \\
\hline Body mass index $\left(\mathrm{kg} / \mathrm{m}^{2}\right)$ & $24.31 \pm 3.02$ & $23.08 \pm 3.26^{\dagger}$ & $22.37 \pm 2.60^{\ddagger}$ & $0.036^{*}$ \\
\hline Educational level & & & & 0.321 \\
\hline Middle school or less & $8(22.2 \%)$ & $3(16.6 \%)$ & $3(15.7 \%)$ & \\
\hline High school & $10(27.7 \%)$ & $10(55.5 \%)$ & $9(47.3 \%)$ & \\
\hline College or more & $18(50.0 \%)$ & $5(27.7 \%)$ & $7(36.8 \%)$ & \\
\hline Monthly income (won) & & & & 0.072 \\
\hline$<1$ million & $7(19.4 \%)$ & $6(33.3 \%)$ & 7 (36.8\%) & \\
\hline 1-3 million & 19 (52.7\%) & 7 (38.8\%) & $8(42.1 \%)$ & \\
\hline >3 million & $10(27.7 \%)$ & $5(27.7 \%)$ & $4(21.0 \%)$ & \\
\hline Menopause (\%) & $10(27.7 \%)$ & $13(66.5 \%)$ & $12(63.1 \%)$ & $0.023^{* *}$ \\
\hline Hematocrit (\%) & 29.8 & 28.1 & 28.3 & 0.057 \\
\hline Testosterone (ng/ml) & $1.25 \pm 2.25$ & $0.45 \pm 0.06^{\dagger}$ & $0.26 \pm 0.08^{\ddagger}$ & $0.027^{*}$ \\
\hline Estradiol (pg/ml) & $80.93 \pm 77.24$ & $27.55 \pm 20.82^{\dagger}$ & $34.68 \pm 55.69^{\ddagger}$ & $0.003^{*}$ \\
\hline Duration of HD (years) & & $7.4 \pm 6.99$ & $8.5 \pm 3.99$ & 0.781 \\
\hline Onset of CRF & & $10.5 \pm 5.29$ & $11.5 \pm 6.72$ & 0.574 \\
\hline Average single-pool Kt/N & & $1.47 \pm 0.11$ & $1.14 \pm 0.05$ & $0.021^{* * *}$ \\
\hline
\end{tabular}

$\mathrm{HD}$, hemodialysis, CRF, chronic renal failure. ${ }^{*}$ analyzed by Kruskal-Wallis test; ${ }^{* *}$ analyzed by Fisher's exact test; ${ }^{* * *}$ analyzed by Mann Whitney test. ${ }^{\dagger}$ Control versus adequate $\mathrm{HD},{ }^{\ddagger}$ Control versus non-adequate HD.

patients with CRF $[14,15]$. Previous studies reported that HD adequacy was not related to female sexual dysfunction. One of the limitations of those studies was the application of the $\mathrm{Kt} / \mathrm{V}$ results. Recently, the recommended dose was increased to a target of 1.4. The KDOQI guidelines (2006) recommend a $\mathrm{Kt} / \mathrm{V}$ dose target of 1.4 with a minimum of 1.2, and the Renal Association Clinical Practice guidelines recommend a single pool Kt/V of greater than 1.3. More importantly, HD adequacy cannot determined by a single $\mathrm{Kt} / \mathrm{V}$, but rather consecutive and consistent target doses of $\mathrm{Kt} / \mathrm{V}$ are more important. In our study, adequate $\mathrm{HD}$ was defined as an average $\mathrm{Kt} / \mathrm{V}$ of 1.3 over three consecutive months.
Although our study did not find an association between HD adequacy and female sexual dysfunction, this is the first study to assess the relation between sexual dysfunction and HD adequacy as measured using the consecutive method in women with CRF.

We reported in a previous study that the score of all domains of the FSFI questionnaire, 'desire', 'arousal', 'lubrication,' 'orgasm,' 'satisfaction' and 'pain', were significantly lower in the patient group than in the control group [16]. However, it is not clear that HD adequacy is related to sexual dysfunction. Our results show that HD adequacy alone does not restore sexual dysfunction in women with CRF. This is in agreement with a report

Table 2 Female sexual function index in patients with chronic renal failure who are on hemodiaysis

\begin{tabular}{|c|c|c|c|c|}
\hline FSFI & Controls $(n=36)$ & Adequate HD $(n=18)$ & Non-adequate HD $(n=19)$ & $P$ value $^{*}$ \\
\hline Desire & $2.4 \pm 0.90,2.4$ & $1.43 \pm 0.68^{\dagger}, 1.2$ & $2.08 \pm 2.47^{\ddagger}, 1.2$ & $<0.001$ \\
\hline Arousal & $2.68 \pm 1.90,3.0$ & $1.11 \pm 1.71^{\dagger}, 0$ & $0.93 \pm 1.87^{\ddagger}, 0$ & 0.001 \\
\hline Lubrication & $3.30 \pm 2.33,3.9$ & $1.66 \pm 2.44^{\dagger}, 0$ & $1.16 \pm 2.33^{\ddagger}, 0$ & 0.004 \\
\hline Orgasm & $2.88 \pm 2.11,3.6$ & $1.48 \pm 2.23^{\dagger}, 0$ & $0.96 \pm 1.93^{\ddagger}, 0$ & 0.004 \\
\hline Satisfaction & $3.45 \pm 1.66,4.0$ & $2.06 \pm 1.70,0.8$ & $2.88 \pm 1.79,4.0$ & 0.052 \\
\hline Pain & $3.37 \pm 2.27,4.0$ & $1.75 \pm 2.59^{\dagger}, 0$ & $1.20 \pm 2.40^{\ddagger}, 0$ & 0.011 \\
\hline Total & $18.11 \pm 10.24,22.0$ & $9.52 \pm 10.64^{\dagger}, 2$ & $8.76 \pm 9.52^{\ddagger}, 5.2$ & 0.003 \\
\hline
\end{tabular}

Values are expressed as mean \pm SD, median value.

$\mathrm{HD}$, hemodialysis; FSFI, Female Sexual Function Index. *analyzed by Kruskal-Wallis test.

${ }^{\dagger}$ Control versus adequate $\mathrm{HD},{ }^{\ddagger}$ Control versus non-adequate HD. 
Table 3 Correlation coefficients between average

\begin{tabular}{ccc}
\multicolumn{2}{c}{ single-pool Kt/V and female sexual function index score } \\
\hline FSFI & Correlation coefficients urea clearance & $\boldsymbol{P}$ value \\
\hline Desire & -0.156 & 0.355 \\
Arousal & 0.194 & 0.250 \\
Lubrication & 0.194 & 0.251 \\
Orgasm & 0.243 & 0.147 \\
Satisfaction & -0.113 & 0.504 \\
Pain & 0.227 & 0.177 \\
Total & -0.052 & 0.761 \\
\hline
\end{tabular}

FSFI, Female Sexual Function Index. *analyzed by Spearman's correlation test.

that sexual dysfunctions does not improve with dialysis treatment [17].

As the genesis of sexual dysfunction is multifactorial in CRF patients, one aspect of HD adequacy alone was insufficient for explaining sexual dysfunction. It is believed that the lack of estradiol-stimulated cyclic LH secretion in women on dialysis leads to ovarian failure, which is presumed to be the primary cause of infertility $[13,15,18,19]$. Our results showed that levels of testosterone and estradiol were significantly decreased in the patient group. Moreover, estradiol showed a significant relationship with the scores in all domains of the FSFI. A previous study demonstrated that hormone replacement therapy allows sustained physiological serum estradiol concentrations in women with estrogen deficiency undergoing HD, with an associated improvement in sexual function [20]. It is suggested that adequate treatment of multiple factors, including emotional derangement and sex hormone change, is also necessary for improvement in sexual function in female CRF patients. Among them, hormonal replacement therapy (HRT) could be a promising treatment option. To date, only $17 \%$ of dialysis women had ever been treated with HRT and even less (6\%) were currently on such therapy [21]. The benefits of HRT in premenopausal women on dialysis with estrogen deficiency treated with transdermal HRT have been reported to show a sustained increase in estrogen and recovery of menstruation [20].

This study had some limitations. First, our patient population was quite small. Generally, the participation rate in sex research is very low and the degree of conservatism in sexual attitudes was very high in those who refused participation. Second, the patients represented only a small geographic area, which limits the generalization of our findings. Third, we did not investigate the depression quantification by questionnaire. Although we excluded those patients with depression, concurrent and subclinical depression could be determined through a questionnaire. However, the diagnostic cut-off values of the Beck depression inventory, which is one of most commonly used questionnaires to assess depression, is not consistent between the DSM-IV criteria and Korean validation form [22]. Therefore, the Beck depression inventory was not applied in our study. Fourth, we have not investigated other factors such as vascular abnormalities, medications, family interactions, and personal and social characteristics. Lastly, this study was not a prospective study. A prospective study of CRF patients is difficult as symptom onset is diverse, and indication and the method of dialysis differ according to each patient's medical condition. Further research, including a multi-center prospective study, is warranted for investigating sexual dysfunction in females with CRF who are undergoing HD.

\section{Conclusion}

In summary, sexual dysfunction was found in women with CRF who were on HD. HD adequacy alone does not have an impact on sexual dysfunction. Our results indicate that new strategies for the treatment of sexual dysfunction in women with CRF who are on HD are needed.

\section{Abbreviations}

CRF: Chronic renal failure; HD: Hemodialysis; FSFI: Female sexual function index; HRT: Hormonal replacement therapy.

\section{Competing interest}

The authors have no competing interest to disclose.

\section{Authors' contributions}

JHK and YSS contributed with the conception and design of the study and drafted the manuscript, SWD, SHK, ISL, and HH collected data and performed the analyses, WJY, ESS, and HJL assisted with conception and design of the study, conceived of the study and supervised the study and helped draft the manuscript. All authors read and approved the final manuscript.

\section{Acknowledgement}

This research was supported by Research Program through the National Research Foundation of Korea (NRF) funded by the Ministry of Education, Science and Technology (2010-0011678) and Soonchunhyang University Research Fund.

\section{Author details}

${ }^{1}$ Department of Urology, Soonchunhyang University Hospital, Soonchunhyang University College of Medicine, Seoul, Korea. ${ }^{2}$ Department of Nephrology, Soonchunhyang University Hospital, Soonchunhyang University College of Medicine, Seoul, Korea. ${ }^{3}$ Department of Obstetrics and Gynecology, Inha University School of Medicine, Incheon, Korea. ${ }^{4}$ Medical Research Institute, Chung-Ang University College of Medicine, Seoul, Korea. ${ }^{5}$ Department of Industrial Management and Engineering, Namseoul University College of Engineering, Cheonan, Korea. ${ }^{6}$ North London Collegiate School, Jeju, Korea.

Received: 10 October 2013 Accepted: 3 January 2014

Published: 8 January 2014

\section{References}

1. Toorians AW, Janssen E, Laan E, Gooren LJ, Giltay EJ, Oe PL, Donker AJ, Everaerd W: Chronic renal failure and sexual functioning: clinical status versus objectively assessed sexual response. Nephrol Dial Transplant 1997, 12(12):2654-2663.

2. Kettas E, Cayan F, Akbay E, Kiykim A, Cayan S: Sexual dysfunction and associated risk factors in women with end-stage renal disease. J Sex Med 2008, 5(4):872-877.

3. Tauchmanova L, Carrano R, Sabbatini M, De Rosa M, Orio F, Palomba S, Cascella T, Lombardi G, Federico S, Colao A: Hypothalamic-pituitarygonadal axis function after successful kidney transplantation in men and women. Hum Reprod 2004, 19(4):867-873. 
4. Basok EK, Atsu N, Rifaioglu MM, Kantarci G, Yildirim A, Tokuc R: Assessment of female sexual function and quality of life in predialysis, peritoneal dialysis, hemodialysis, and renal transplant patients. Int Urol Nephrol 2009, 41(3):473-481.

5. Muehrer RJ, Keller ML, Powwattana A, Pornchaikate A: Sexuality among women recipients of a pancreas and kidney transplant. West J Nurs Res 2006, 28(2):137-150. discussion 151-161.

6. Filocamo MT, Zanazzi M, Li Marzi V, Lombardi G, Del Popolo G, Mancini G, Salvadori M, Nicita G: Sexual dysfunction in women during dialysis and after renal transplantation. J Sex Med 2009, 6(11):3125-3131.

7. Eknoyan G, Beck GJ, Cheung AK, Daugirdas JT, Greene T, Kusek JW, Allon M, Bailey J, Delmez JA, Depner TA, et al: Effect of dialysis dose and membrane flux in maintenance hemodialysis. N Engl J Med 2002, 347(25):2010-2019.

8. Daugirdas JT: Second generation logarithmic estimates of single-pool variable volume Kt/V: an analysis of error. J Am Soc Nephrol 1993, 4(5):1205-1213.

9. Meston CM: Validation of the female sexual function index (FSFI) in women with female orgasmic disorder and in women with hypoactive sexual desire disorder. J Sex Marital Ther 2003, 29(1):39-46.

10. Rosen R, Brown C, Heiman J, Leiblum S, Meston C, Shabsigh R, Ferguson D, D'Agostino R Jr: The female sexual function index (FSFI): a multidimensional self-report instrument for the assessment of female sexual function. J Sex Marital Ther 2000, 26(2):191-208.

11. Hy K, Hs S, KS P, Jeong SJ, Lee JY, Ryu SB: Development of the Korean-version of female sexual function index (FSFI). Korean J Androl 2002, 20(1):50-56.

12. Diemont WL, Vruggink PA, Meuleman EJ, Doesburg WH, Lemmens WA, Berden JH: Sexual dysfunction after renal replacement therapy. Am J Kidney Dis 2000, 35(5):845-851.

13. Zingraff J, Jungers $P$, Pelissier $C$, Nahoul K, Feinstein MC, Scholler R: Pituitary and ovarian dysfunctions in women on haemodialysis. Nephron 1982, 30(2):149-153.

14. Neto AF, de Freitas Rodrigues MA, Saraiva Fittipaldi JA, Moreira ED Jr: The epidemiology of erectile dysfunction and its correlates in men with chronic renal failure on hemodialysis in Londrina, southern Brazil. Int J Impot Res 2002, 14(2):S19-26.

15. Peng YS, Chiang CK, Kao TW, Hung KY, Lu CS, Chiang SS, Yang CS, Huang YC, Wu KD, Wu MS, et al: Sexual dysfunction in female hemodialysis patients: a multicenter study. Kidney Int 2005, 68(2):760-765.

16. Song YS, Yang HJ, Song ES, Han DC, Moon C, Ku JH: Sexual function and quality of life in Korean women with chronic renal failure on hemodialysis: case-control study. Urology 2008, 71(2):243-246.

17. Soykan A, Boztas H, Kutlay S, Ince E, Nergizoglu G, Dilekoz AY, Berksun O: Do sexual dysfunctions get better during dialysis? Results of a six-month prospective follow-up study from Turkey. Int J Impot Res 2005, 17(4):359-363.

18. Mastrogiacomo I, De Besi L, Serafini E, Zussa S, Zucchetta P, Romagnoli GF, Saporiti E, Dean P, Ronco C, Adami A: Hyperprolactinemia and sexual disturbances among uremic women on hemodialysis. Nephron 1984, 37(3):195-199.

19. Oksuz E, Malhan S: Prevalence and risk factors for female sexual dysfunction in Turkish women. J Urol 2006, 175(2):654-658. discussion 658.

20. Matuszkiewicz-Rowinska J, Skorzewska K, Radowicki S, Sokalski A, Przedlacki J, Niemczyk S, Wlodarczyk D, Puka J, Switalski M: The benefits of hormone replacement therapy in pre-menopausal women with oestrogen deficiency on haemodialysis. Nephrol Dial Transplant 1999, 14(5):1238-1243.

21. Kramer HM, Curhan GC, Singh A: Permanent cessation of menses and postmenopausal hormone use in dialysis-dependent women: the HELP study. Am J Kidney Dis 2003, 41(3):643-650.

22. Koo JR, Yoon JW, Kim SG, Lee YK, Oh KH, Kim GH, Kim HJ, Chae DW, Noh JW, Lee SK, et al: Association of depression with malnutrition in chronic hemodialysis patients. Am J Kidney Dis 2003, 41(5):1037-1042.

doi:10.1186/1471-2490-14-4

Cite this article as: Kim et al: Association between the hemodialysis adequacy and sexual dysfunction in chronic renal failure: a preliminary study. BMC Urology 2014 14:4.

\section{Submit your next manuscript to BioMed Central and take full advantage of:}

- Convenient online submission

- Thorough peer review

- No space constraints or color figure charges

- Immediate publication on acceptance

- Inclusion in PubMed, CAS, Scopus and Google Scholar

- Research which is freely available for redistribution

Submit your manuscript at www.biomedcentral.com/submit
C Biomed Central 